\title{
Sex Trading and Psychological Distress Among Women on Methadone
}

Nabila El-Bassel [a], Jane M. Simoni [b], Daniel K. Cooper [c], Louisa Gilbert [a], Robert F. Schilling [d]

[a] Social Intervention Group, School of Social Work, Columbia University

[b] Department of Psychology, Yeshiva University

[c] Department of Social Sciences, York College

[d] School of Public Policy and Social Research, University of California, Los Angeles

Jane M. Simoni is now at the Department of Psychology, University of Washington.

Portions of this article were originally presented at the meeting of the American Public Health Association, New York, October 1996; the Conference of Psychosocial and Behavioral Factors in Women's Health: Research, Prevention, Treatment, and Service Delivery in Clinical and Community Settings, Washington, DC, September 1996; and the 11th International Conference on AIDS, Vancouver, British Columbia, Canada, July 1996. The study was supported by a grant from the National Institute on Drug Abuse (RO1DA08005) to Robert F. Schilling.

Correspondence concerning this article should be addressed to Nabila El-Bassel, Social Intervention Group, School of Social Work, Columbia University, 622 West 113th Street, New York, New York 10025. Email: ne5@columbia.edu.

\begin{abstract}
This study examined the relationship between sex trading and psychological distress among a nonrandom sample of women recruited from 3 methadone maintenance clinics in New York City. Face-to-face interviews with 280 women (M age $=40.7)$ revealed that $32 \%$ had traded sex for money or drugs in the previous year. Compared to other participants, these women reported less education and higher rates of incarceration in the past year, sexually transmitted diseases, childhood sexual abuse, partner abuse, and current regular crack/cocaine and alcohol use. Hierarchical multiple regression analysis indicated that sex traders scored 0.41 units higher than non-sex traders on the General Severity Index of the Brief Symptom Inventory after controlling for all relevant covariates. The findings emphasize the need to consider the interrelation of psychological distress, abuse, and addiction in designing public health interventions addressing methadone maintained women.
\end{abstract}

\section{Introduction}

Women who exchange sex for money, drugs, or other favors are at increased risk for sexually transmitted disease (STDs), including HIV. Research suggests that designing sexual risk reduction strategies for these women may require understanding the relationship between sex trading and psychological distress. Specifically, several studies of mentally ill, drug-abusing, and homeless populations have found that individuals with multiple sex partners and those who 
engage in other high-risk sexual behaviors exhibit higher levels of psychological distress and psychiatric symptomatology (Kelly et al., 1992; Kelly et al., 1993; Nemoto, Foster, \& Brown, 1991; Nyamathi, 1992; Susser, Valencia, \& Conover, 1993). One of the first studies to examine the association between psychological status and HIV risk behaviors among sex workers indicated that injecting drugs and engaging in unprotected intercourse were strongly associated with a high level of depressive symptomatology (Alegria et al., 1994). More recently, in a study of 477 men recruited from the streets of Harlem, sex traders reported more psychological distress than non-sex traders even after adjusting for perceived AIDS risk, current regular crack cocaine use, and homelessness (El-Bassel et al., 2000). In a related study of 346 women, those who had exchanged sex for money or drugs in the past 30 days had higher levels of psychological distress than those who had not, after adjusting for crack cocaine use, perceived risk of AIDS, history of rape, and other potentially confounding variables (El-Bassel et al., 1997).

The relationship between sex trading and psychological distress among active drug abusers may be confounded by the effects of drug use on psychological distress. Studies have established an association between cocaine dependence and psychological distress and psychiatric symptomatology, in particular antisocial and borderline personality disorders (Bunt, Galanter, Lifshutz, \& Castaneda, 1990; Kleinman et al., 1990). Crack-addicted sex workers, who report low rates of condom use and high numbers of sexual partners (Chiasson et al., 1991; Edlin et al., 1992; R. E. Fullilove, Fullilove, Bowser, \& Gross, 1990; Marx, Sevgi, Rolfs, Sterk, \& Kahn, 1991; Rolfs, Goldberg, \& Sharrar, 1990; Zweig Greenberg, Singh, Htoo, \& Schultz, 1991), may be especially vulnerable to psychological distress because of the degrading and perilous circumstances they face when exchanging sex for money or drugs (Chiasson et al., 1991; Edlin et al., 1994; Edlin et al., 1992; R. E. Fullilove et al., 1990; Irwin et al., 1995; Marx et al., 1991; Rolfs et al., 1990; Zweig Greenberg et al., 1991). Previous research also has documented associations between psychological distress and dependence on opiates (Darke, Wodak, Hall, Heather, \& Ward, 1992; Malow, West, Williams, \& Sutker, 1989) and alcohol (Lesswing \& Dougherty, 1993; Nolimal \& Crowley, 1989), both of which are commonly used by sex workers (Gossop, Griffiths, Powis, \& Strang, 1993; Green et al., 1994; Inciardi, 1992; McBride, Inciardi, Cudweed, \& McCoy, 1992; Plant, Plant, Peck, Setters, \& Setters, 1989; Schilling et al., 1994).

The relationship between sex trading and psychological distress also may be complicated by the experiences of early sexual and physical abuse, both of which are demonstrably more common among drug-involved women and sex traders than among women in the general population (Irwin et al., 1995). Adults who were sexually or physically abused as children are vulnerable to low self-esteem, anxiety, suicide, sexual difficulties, interpersonal problems, and repeated victimization in adulthood (Cloitre, Tardiff, Marzuk, Leon, \& Portera, 1996; Johnsen \& Harlow, 1996; Mullen, Martin, Anderson, Romans, \& Herbison, 1996). Many report more frequent and longer durations of depression and anxiety compared to those without histories of trauma (Gold, Milan, Mayall, \& Johnson, 1994; Simoni \& Ng, 2000; Zlotnick, Warsaw, Shea, \& Keller, 1997). Women who were sexually abused in childhood also report significantly higher frequencies of prostitution and sex with strangers (Zierler et al., 1991), less assertiveness in negotiating safe sex practices, and less efficacy concerning HIV prevention (Johnsen \& Harlow, 1996).

Childhood abuse is often related to later trauma, including partner abuse, which also may complicate the association between sex trading and psychological distress among female drug 
abusers. An estimated $60 \%-75 \%$ of the women in substance abuse treatment programs have experienced partner violence in their lifetime (Dunn, Ryan, \& Dunn, 1994; Gil-Rivas, Fiorentine, \& Anglin, 1996; Paone, Chavkin, Willets, Friedman, \& Des Jarlais, 1992; Resnick, Kilpatrick, Dansky, Saunders, \& Best, 1993; Windle, Windle, Scheidt, \& Miller, 1995), rates that are two to three times higher than the rates found in national surveys of women in the general population (Straus, Gelles, \& Steinmetz, 1980). Partner violence has been shown to be associated with drug and alcohol abuse (Zierler et al., 1991; Zweig Greenberg et al., 1991) and HIV risk among women who exchange sex for money or drugs (El-Bassel et al., 1997; Irwin et al., 1995).

Researchers have begun to address some important questions regarding the epidemiology and etiology of psychological distress among sex traders; however, the association of sex trading and psychological distress has yet to be examined specifically among women in methadone treatment. Methadone maintenance is an effective treatment for heroin addiction, thereby decreasing the risk for HIV infection associated with needle sharing behaviors (Ball \& Ross, 1991). However, several factors remain to be addressed in order to improve its efficacy, including reports of opiate, cocaine, and alcohol use; program attrition; and sexual risk-taking behaviors (Roszell, Calsyn, \& Chaney, 1986; Schilling, El-Bassel, Hadden, \& Gilbert, 1995). Psychological distress may be another factor, possibly related to these problems, that detracts from program effectiveness. Previous research with 75 methadone maintenance clinic patients indicated a high prevalence of psychiatric diagnoses, with depression, phobias, antisocial personality, and generalized anxiety found to be the most common (Mason et al., 1998). Number of diagnoses and severity of psychopathology were related to concurrent drug use as well as familial and social problems. In a study of 158 female methadone users in Los Angeles, HIV risk behaviors were associated with suicidality and depression as well as alcohol and polydrug use (Grella, Anglin, \& Annon, 1996).

Because of their regular and frequent clinic visits, methadone patients are a highly accessible population toward whom it may be possible to target public health risk reduction interventions. Deciphering the complex relationship between sex trading and psychological distress would inform the development of such interventions. Some research has already begun to explore these possibilities. For example, among 353 injection drug users, retention in methadone maintenance was associated with reductions in risk behaviors; women who stayed in treatment reported significantly fewer injection drug-abusing partners at a 1-year follow-up (Wells, Calsyn, Clark, Saxon, \& Jackson, 1996). In addition, Bellis (1993) reported a reduction in HIV risk among 41 heroin-addicted female prostitutes on methadone maintenance. Finally, our own research has shown that skills-training groups can effectively teach female methadone patients to reduce their risk for heterosexual HIV transmission (El-Bassel \& Schilling, 1992; Schilling, El-Bassel, Schinke, Gordon, \& Nichols, 1991; Schilling, El-Bassel, Hadden, \& Gilbert, 1995).

In this study we assessed the level of psychological distress among a sample of poor, inner-city women on methadone maintenance and examined the hypothesis that, after controlling for relevant demographics, childhood abuse, partner abuse, and drug use, sex trading would be associated with higher levels of psychological distress.

\section{Method}




\section{Sample Recruitment}

Study participants were recruited through printed announcements posted on the walls of three methadone clinics in Harlem and through methadone program staff referrals during a 9-month period between 1995 and 1996. To be eligible for the study, participants had to be between the ages of 18 and 55, currently enrolled as patients at one of the three clinics for at least 3 months, sexually active, and not always using condoms in the previous 90 days. Participants also had to report one or more of the following HIV-risk behaviors in the past year: having sex with a new partner; having an STD; having sex with more than one partner; injecting drugs; smoking crack; having sex with someone they knew was having sex with someone else; or having sex with someone who was injecting drugs, HIV-infected, or had an STD. These eligibility criteria were designed to select women who would be at risk of heterosexual HIV transmission and, thus, representative of women who might benefit from an HIV prevention intervention that was part of the larger study. Trained female interviewers conducted face-to-face structured interviews with participants, who received $\$ 20$ for their time.

\section{Participants}

The baseline questionnaire was administered to 335 women, $91 \%$ of whom were African American, Latina, or White. We excluded the other 9\% (11 who reported an "other" ethnicity and 19 with missing data for ethnic classification) as well as the 25 respondents with missing data on any of the main variables. The final sample, therefore, consisted of 280 women: Latinas (42\%), African Americans (49\%), and European Americans (9\%). Their mean age was 40.7 years $(\mathrm{SD}=6.7)$, and their mean years of education was $11.6(\mathrm{SD}=2.0) ; 80 \%$ were on public assistance. Currently, $15 \%$ were married; $41 \%$ were living with a sex partner; $24 \%$ were separated, widowed, or divorced; and $20 \%$ had never been married. More than half the respondents $(58 \%)$ had children under the age of 18 . Twenty percent reported homelessness in the past year, and $20 \%$ had been incarcerated at some point in their lives. Measures

Demographic variables were age, years of education, ethnicity, marital status, sources of income, and children under 18. We also asked respondents about their history of STDs, homelessness, and incarceration. Sex traders were defined as women who responded "yes" to the item "During the past year, did you have sex with someone to get money and/or drugs?" With one item for each of a variety of drugs, we assessed the frequency of drug use during the past year on an 8point scale that ranged from never to 3 or more times per day. In this study, current regular drug use was defined as having used any of the following drugs three times per week or more during the past year: injection drugs (i.e., heroin, cocaine, and speedball) as well as alcohol, nasal heroin, and noninjection crack/cocaine.

Abuse was assessed with four yes-no items. For childhood physical abuse, the item was "Before you were 16 years old, were you ever punched, pushed, hit, bit, shoved, kicked, whipped, beaten, or suffered painful physical injuries - beyond what you considered discipline-from your parents, caretaker, or guardian?" For childhood sexual abuse we asked, 
Think about the time when you were growing up, before you were 13 years old. During that period - before you were 13 - did you ever have unwanted or uninvited sexual activity with anyone who was 5 or more years older than you?

To evaluate partner physical abuse we queried, "Have you ever been choked or strangled or physically threatened with a knife or gun by a boyfriend or spouse?" Finally, we operationalized partner sexual abuse by asking, "Did your boyfriend or spouse ever force you to have sex when you didn't want to?"

Psychological distress was assessed with 51 of the 53 items of the Brief Symptom Inventory (BSI), a scale of self-reported symptoms of psychological distress experienced during the previous 7 days (Broday \& Mason, 1991; Derogatis \& Melisaratos, 1983). Each item is rated on a scale that ranges from 0 (never) to 4 (always). Individual subscales assess nine primary symptom dimensions. The General Severity Index (GSI) is a weighted frequency score based on the sum of the ratings of all items. Derogatis and Melisaratos (1983) reported a mean GSI score of $1.32(\mathrm{SD}=0.72)$ among a sample of 1,002 psychiatric outpatients and a mean of 1.36 in a sample of 313 psychiatric inpatients; the nonpatient norm was $\mathrm{M}=0.30(\mathrm{SD}=0.31)$. Previous studies have found very good test-retest and internal consistency reliabilities and high correlations with the comparable dimensions of the Symptom Checklist-90-Revised (Broday \& Mason, 1991; Derogatis \& Cleary, 1977; Derogatis \& Melisaratos, 1983).

\section{Results}

Sex Traders Versus Non-Sex Traders: Bivariate Analyses

Overall, $32 \%$ of the sample reported trading sex. As seen in Table 1, bivariate comparisons of sex traders and non-sex traders indicate that sex traders were slightly less educated and were more likely to have been incarcerated in the past year. With respect to sources of income, sex traders, not surprisingly, reported being more likely than non-sex traders to receive support from families, friends, and sex partners and to receive income from illegal activity. Compared to women who did not trade sex, sex traders also reported a higher lifetime prevalence for STDs. The two groups did not differ according to any other demographic or background indicator. 
Table 1

Differences Between Non-Sex Traders and Sex Traders

\begin{tabular}{|c|c|c|}
\hline Variable & $\begin{array}{l}\text { Non-sex traders } \\
(n=191,68 \%)\end{array}$ & $\begin{array}{c}\text { Sex traders } \\
(n=89,32 \%)\end{array}$ \\
\hline Age $(M / S D)$ & $40.8 / 6.9$ & $40.6 / 6.5$ \\
\hline Years of education** (M/SD) & $11.8 / 2.1$ & $11.2 / 1.7$ \\
\hline \multicolumn{3}{|l|}{ Ethnicity } \\
\hline Latina & 40.1 & 46.1 \\
\hline African American & 50.0 & 48.3 \\
\hline European American & 9.9 & 5.6 \\
\hline \multicolumn{3}{|l|}{ Marital status } \\
\hline Married & 16.8 & 12.4 \\
\hline Living w/sex partner & 42.6 & 38.2 \\
\hline Separated/divorced/widowed & 23.2 & 24.7 \\
\hline Never married & 17.4 & 24.7 \\
\hline Children under 18 & 60.4 & 52.8 \\
\hline Homeless during past year & 20.4 & 19.3 \\
\hline Incarcerated during past year*** & 14.7 & 31.5 \\
\hline \multicolumn{3}{|l|}{ Source of income } \\
\hline Wages/salary from job & 18.2 & 21.6 \\
\hline Wages/salary from spouse's job & 15.1 & 13.6 \\
\hline Family/friends/sex partner**** & 28.6 & 46.6 \\
\hline Supplemental Security Income & 20.3 & 22.7 \\
\hline Aid to Families With Dependent Children & 80.2 & 80.7 \\
\hline Food stamps & 69.8 & 71.6 \\
\hline Illegal activity***** & 5.2 & 28.4 \\
\hline \multicolumn{3}{|l|}{ Sexually transmitted disease history } \\
\hline Ever had syphilis**** & 15.9 & 37.7 \\
\hline Ever had gonorrhea** & 17.9 & 31.5 \\
\hline Ever had trichomonos** & 17.5 & 30.3 \\
\hline Ever had chlamydia***** & 9.6 & 24.7 \\
\hline \multicolumn{3}{|l|}{ Abuse history } \\
\hline Childhood physical abuse & 33.9 & 44.9 \\
\hline Childhood sexual abuse*** & 25.5 & 41.6 \\
\hline Partner physical abuse*** & 37.0 & 52.8 \\
\hline Partner sexual abuse**** & 27.1 & 43.8 \\
\hline \multicolumn{3}{|l|}{ Current drug use pattern } \\
\hline Regularly injects drugs & 14.6 & 23.6 \\
\hline Regular noninjection crack/cocaine use $* * * *$ & 25.0 & 62.9 \\
\hline Regular nasal heroin use & 11.5 & 15.7 \\
\hline Regular alcohol use***** & 19.8 & 42.7 \\
\hline
\end{tabular}

Note. All numbers are percentages except where noted.

${ }^{* *} p<.05 .{ }^{* * *} p<.01 .{ }^{* * * *} p<.005$.

Abuse levels were high throughout the sample, but sex traders were more likely than non-sex traders to have suffered childhood abuse (see Table 1). They also were more likely to have been choked, strangled, or physically threatened by a partner and more likely to have been forced by a partner to have sex. With respect to drug use (see Table 1), sex traders were more likely than non-sex traders to have used noninjection crack/cocaine and alcohol two to three times per week or more during the past year.

\section{Sex Trading and Psychological Distress}

Means scores on the BSI for the sample overall were well above the nonpatient norm of 0.30 (Derogatis \& Melisaratos, 1983). As seen in Table 2, sex traders reported significantly more psychological distress than non-sex traders did. Across all BSI subscales, sex traders scored at least $45 \%$ higher than non-sex traders, and sex traders reported a mean BSI GSI score 0.54 points higher than that of non-sex traders. These differences were all significant beyond the .005 level. 
Table 2

Sex Trading and Psychological Distress

\begin{tabular}{lccccc}
\hline & \multicolumn{2}{c}{$\begin{array}{c}\text { Non-sex traders } \\
(n=191,68 \%)\end{array}$} & & \multicolumn{2}{c}{$\begin{array}{c}\text { Sex traders } \\
(n=89,32 \%)\end{array}$} \\
\cline { 2 - 3 } \multicolumn{1}{c}{ BSI scale } & $M$ & $S D$ & & $M$ & $S D$ \\
\hline Somatic**** & 0.82 & 0.83 & & 1.19 & 0.92 \\
Obsessive Compulsive**** & 1.08 & 0.97 & & 1.75 & 0.95 \\
Interpersonal Sensitivity**** & 0.94 & 0.92 & & 1.60 & 1.10 \\
Depression**** & 1.01 & 1.02 & & 1.53 & 1.06 \\
Anxiety***** & 0.89 & 0.94 & & 1.49 & 1.06 \\
Hostility**** & 0.88 & 0.86 & & 1.39 & 0.99 \\
Phobic Anxiety**** & 0.52 & 0.79 & & 0.91 & 1.00 \\
Paranoid Ideation**** & 0.99 & 0.95 & 1.67 & 1.04 \\
Psychoticism***** & 0.69 & 0.80 & & 1.22 & 0.97 \\
Global Severity Index**** & 0.88 & 0.76 & & 1.42 & 0.83 \\
\hline
\end{tabular}

Note. $\quad$ BSI $=$ Brief Symptom Inventory.

$* * * * p<.005$.

We next used a hierarchical multiple regression model to examine the relationship between sex trading and psychological distress. In this model, we entered successively each set of covariates (i.e., demographics, childhood abuse, partner abuse, and drug use) to identify the proportion of variance it explained (see Table 3).

Table 3

Regression Model of Sex Trading and Psychological Distress

\begin{tabular}{lcc}
\hline \multicolumn{1}{c}{ Variable set } & Coefficient & Change in adjusted $R^{2}$ \\
\hline Demographics & & $.12 * * * *$ \\
Age & -.01 & \\
African American**** & -.35 & \\
White & -.28 & \\
Years of education** & -.04 & $.04 * * * *$ \\
Incarcerated during past year*** & .28 & \\
Childhood abuse & .32 & $.01 * *$ \\
Physical**** & -.11 & \\
Sexual & .21 & $.02 *$ \\
Partner abuse & .02 & \\
Physical*** & & \\
Sexual & .01 & \\
Current regular drug use & \\
Injection drug & .03 & $.03 * * * *$ \\
Noninjection crack/cocaine & -.08 & $.22 * * * *$ \\
Nasal heroin & .19 & \\
Current regular alcohol** & .35 & \\
Sex trading: Had sex to get money or drugs, past year**** & & \\
Model & & \\
\hline
\end{tabular}

"Ethnic reference group is Latina. ${ }^{b}$ Two to three times per week.

${ }^{*} p<.10 .{ }^{* *} p<.05 .{ }^{* * *} p<.01 .{ }^{* * * *} p<.005$.

According to the unstandardized regression coefficients, sex traders scored 0.30 points higher on the GSI than did non-sex traders. The model explained $22 \%$ of the variance in GSI scores, with trading sex for money or drugs explaining $3 \%$ of the variance in the GSI score over and above the combined $18 \%$ explained by the four sets of control variables (the $3 \%$ and the $18 \%$ do not sum to the $22 \%$ total explained variance because of rounding error). Although all four sets of control variables explained a statistically significant proportion of the variation in the GSI score, a few individual control variables stand out. Specifically, Latinas scored 0.35 points higher on 
the GSI than did African Americans, and those who reported childhood physical abuse and partner physical abuse scored 0.32 points and 0.21 points higher, respectively, than those who did not.

\section{Discussion}

The findings from this study of 280 female methadone users indicate that $32 \%$ had received money or drugs in exchange for sex in the previous year. Compared to other participants, sex traders reported less education and higher rates of incarceration in the past year, STDs, childhood sexual abuse, partner abuse, and current regular crack/cocaine and alcohol use. Sex traders also had significantly higher scores than non-sex traders on all nine subscales of the BSI. Hierarchical regression analysis confirmed the hypothesis that sex traders would be more likely than non-sex traders to exhibit psychological distress, even after adjusting for differences in demographics, childhood abuse, partner abuse, and drug use. Indeed, sex traders in this sample had a higher mean GSI score than samples of psychiatric outpatients and inpatients. Women who did not trade sex also had distress levels substantially higher than the population norm. Although other recent studies have found an association between sexual risk behaviors and psychological distress among people receiving care in medical and mental health facilities (Kelly et al., 1992; Nyamathi, 1992; Susser et al., 1993), male sex traders (El-Bassel et al., 2000), and streetrecruited inner-city women (El-Bassel et al., 1997), this is the first study to report this relationship among methadone maintained women.

Our finding that sex traders had higher scores than non-sex traders on the Psychoticism and Depression subscales of the BSI is consistent with previous research linking hypersexuality, indiscriminate sexual activity, and impulsive sexual behavior with schizophrenia, bipolar illness, and borderline personality disorder (Kelly et al., 1993). Other studies have documented an association between sex trading and multiple traumas, drug use, and other characteristics associated with psychological distress (Bouknight, 1990; Breslau, Davis, Andreski, \& Peterson, 1991; M. T. Fullilove, Lown, \& Fullilove, 1992; Sterk \& Elifson, 1990). These associations notwithstanding, the extent to which psychological distress is a precursor or a sequela of sex trading remains unanswered by this study. Although prospective studies are needed to evaluate the temporal relationships between sex trading and psychological distress, it is possible that the causal pathways are bidirectional. Psychological distress, perhaps itself the result of early sexual abuse, may manifest in sex trading. At the same time, the stressful and degrading aspects of sex trading may directly contribute to decreased psychological well-being. Future research might also consider treatment parameters (e.g., methadone dose, consistency of attendance) that might correlate with psychological indicators.

Several methodological limitations of this study must be acknowledged. First, the nonrandom sampling strategy limits the extent to which we can generalize the findings to other groups of women on methadone maintenance and, certainly, to other groups of drug abusers in general. Second, a social desirability bias may have led participants to underestimate their involvement in sex trading and drug use behavior. On a related note, it is possible, although less plausible, that some women may have overreported any of the problem phenomena, including sexual abuse, tapped by means of the questionnaire battery. Third, we did not control for all the possible other stressful life events that may more fully account for psychological distress in our sample (e.g., 
community violence, nonpartner sexual assault). Finally, our operationalization of a few key constructs limits our ability to interpret the findings. For example, our definition of sex traders did not allow us to distinguish between women who traded sex primarily for money and those who traded primarily for drugs. Future researchers may want to explore this distinction. In addition, our measures of childhood and partner abuse were somewhat more limited than those used by other researchers and may have led to the lower rates of abuse reported in this study. Furthermore, this may explain the nonassociation between childhood sexual abuse and psychological distress that we reported.

Despite these limitations, this study has implications for serving women on methadone who trade sex. First, the higher level of psychological distress among methadone maintained sex traders underscores the need to assess and treat psychiatric symptomatology in this population (see King \& Brooner, 1999). The unexpected finding that Latinas reported greater distress than African Americans suggests they may be at particular psychological risk, although we can think of no plausible post hoc explanation for this finding. The stigma sex traders experience because of the nature and illegal status of their work likely contributes to their psychological distress (M. T. Fullilove et al., 1992) as well as their reluctance to seek treatment. Although not specifically examined in this study, psychological distress may contribute to concurrent substance abuse and undermine the efficacy of methadone treatment. The feasibility, accessibility, and desirability of mental health services offered directly at methadone clinics requires further empirical consideration (see Kidorf, King, \& Brooner, 1999).

Second, sex traders were more likely to report a history of STDs. One study of 790 methadone patients in the Bronx demonstrated that a specific STD — syphilis—reflected high-risk sexual activity and was associated with acquiring HIV infection (Gourevitch et al., 1996). Adopting and maintaining safer sex behaviors requires motivation to change, ability to anticipate risky situations, and problem-solving and social skills to negotiate condom use — all of which might be impeded by psychological distress. HIV prevention programs targeting women on methadone, therefore, should consider how psychological distress may hinder such women from reducing HIV-risk behavior. For example, women who are clinically depressed may have low self-esteem and high levels of guilt and shame, which may undermine their assertiveness in negotiating condom use. Psychotherapeutic or psychopharmacological intervention to address the underlying depression may lessen feelings of personal worthlessness, apathy, and lethargy and lead to greater motivation for and commitment to behavioral change.

Third, sex traders reported higher rates of partner abuse and substance use (currently regular crack/cocaine and alcohol) than other women. Attempts to address their psychological distress and sexual risk behavior, therefore, will best incorporate a consideration of these issues. Counselors should be sensitive to the issues of trauma, such as maladaptive coping and revictimization experiences (see Simoni \& Ng, 2000), and should realize that an abused woman who promotes condom use may risk further partner violence. Stitzer and Chutuape (1999) suggested that substance use be actively addressed in the methadone patient's treatment plan. For cocaine use, they recommend intensified counseling and urine surveillance as first steps and more potent positive and negative incentives as needed. Alcohol use needs to be identified early and may be amenable to disulfiram treatment and routine alcohol breath monitoring. 
Fourth, for many women who trade sex, such activity constitutes their major source of income. These women, as well as those engaged in "survival sex," who have no other income source, must not only reduce their dependence on drugs but also secure alternative financial support, such as public assistance, to reduce their dependency on sex trading. Those who are not ready or able to leave sex trading may benefit from efforts to reduce associated risks of HIV and violence within a harm reduction framework. In any event, public health interventions targeting methadone maintained sex traders are likely to fail unless such interventions are integrated with other basic services, such as housing, public assistance, education, and viable employment opportunities.

The easy access to patients in methadone treatment, given their almost daily attendance, suggests that interventions with this group may be successful. Federal regulations require programs to provide supportive services along with methadone treatment; however, most programs have limited services beyond dispensing medication, and resources for supportive programs have eroded in recent years (Ball \& Corty, 1988; Hubbard et al., 1989). In addition, the complex psychological, medical, and social needs of methadone maintained women who trade sex may strain the resources of most methadone clinics, necessitating adjunctive services in other settings. Our findings suggest that these women need ancillary supportive services, including psychological counseling, which have shown to be effective with men (McLellan, Arndt, Metzger, Woody, \& O’Brien, 1993). Such therapeutic interventions, moreover, would appear to be most potent if provided in the context of an array of services that address their multiple, longstanding needs.

\section{References}

Alegria, M., Vera, M., Freeman, D. H., Robles, R., Santos, M., \& Rivera, C. (1994). HIV infection, risk behaviors and depressive symptoms among Puerto Rican sex traders. American Journal of Public Health, 84, 2000-2002.

Ball, J. C., \& Corty, E. (1988). Basic issues pertaining to the effectiveness of methadone maintenance treatment. In C. G. Leukyfeld \& F. M. Tims (Eds.), Compulsory treatment of drug abuse: Research and clinical practice (NIDA Research Monograph No. 86, pp. 178-191). Rockville, MD: National Institute on Drug Abuse.

Ball, J. C., \& Ross, A. (1991). The effectiveness of methadone maintenance treatment. New York: Springer-Verlag.

Bellis, D. J. (1993). Reduction of AIDS risk among 41 heroine addicted female street prostitutes: Effects of free methadone maintenance. Journal of Addictive Diseases, 12, 7-23.

Bouknight, L. G. (1990). The public health consequences of crack cocaine. New York State Journal of Medication, 90, 493-495.

Breslau, N., Davis, G. C., Andreski, P., \& Peterson, E. (1991). Traumatic events and posttraumatic stress disorder in an urban population of young adults. Archives of General Psychiatry, 48, 216-222. 
Broday, S. F., \& Mason, J. L. (1991). Internal consistency of the Brief Symptom Inventory for counseling-center clients. Psychological Reports, 6, 94.

Bunt, G., Galanter, M., Lifshutz, H., \& Castaneda, R. (1990). Cocaine/“crack” dependence among psychiatric inpatients. American Journal of Psychiatry, 147, 1542-1546.

Chiasson, M. A., Stoneburner, R. L., Hildebrandt, D. S., Ewing, W. E., Telzak, E. E., \& Jaffe, H. A. W. (1991). Heterosexual transmission of HIV-1 associated with the use of smokable freebase cocaine (crack). AIDS, 5, 1121-1126.

Cloitre, M., Tardiff, K., Marzuk, P. M., Leon, A. C., \& Portera, L. (1996). Childhood abuse and subsequent sexual assault among female inpatients. Journal of Traumatic Stress, 9, 473-482.

Darke, S., Wodak, A., Hall, W., Heather, N., \& Ward, J. (1992). Prevalence and predictors of psychopathology among opioid users. British Journal of Addiction, 82, 771-776.

Derogatis, L. R., \& Cleary, P. A. (1977). Confirmation of the dimensional structure of the SCL90-R: A study in construct validation. Journal of Clinical Psychology, 33, 981-989.

Derogatis, L. R., \& Melisaratos, N. (1983). The Brief Symptom Inventory: An introductory report. Psychological Medicine, 13, 595-605.

Dunn, G., Ryan, J., \& Dunn, C. (1994). Trauma symptoms in substance abusers with and without histories of childhood abuse. Journal of Psychoactive Drugs, 26, 357-360.

Edlin, B. R., Irwin, K. L., Faruque, S., McCoy, C. B., Word, C., Serrano, Y., Inciard, J. A., Bowser, B. P., Schilling, R. F., \& Holmberg, S. D. (1994). Intersecting epidemics: Crack cocaine use and HIV infection among inner-city young adults. New England Journal of Medicine, 331, $1422-1427$.

Edlin, B. R., Irwin, K. L., Ludwig, D. D., McCoy, H. V., Serrano, Y., Word, C., Bowser, B. P., Faruque, S., McCoy, C. B., \& Schilling, R. F. (1992). High-risk sex behavior among young street-recruited crack cocaine smokers in three American cities: An interim report. Journal of Psychoactive Drugs, 24, 363-371.

El-Bassel, N., \& Schilling, R. F. (1992). Fifteen month follow-up of women methadone patients taught skills to reduce heterosexual HIV transmission. Public Health Reports, 107, 500-503.

El-Bassel, N., Schilling, R. F., Gilbert, L., Faruque, S., Irwin, K. L., \& Edlin, B. R. (2000). Sex trading and psychological distress in a street-based sample of low-income urban men. Journal of Psychoactive Drugs, 32, 259-267.

El-Bassel, N., Schilling, R. F., Irwin, K. L., Faruque, S., Gilbert, L., Von Bargen, J., Seranno, Y., \& Edlin, B. (1997). Sex trading and psychological distress among women recruited from the streets of Harlem. American Journal of Public Health, 87, 66-70. 
Fullilove, M. T., Lown, A., \& Fullilove, R. E. (1992). Crack 'hos and skeezers': Traumatic experiences of women crack users. Journal of Sex Research, 29, 275-287.

Fullilove, R. E., Fullilove, M. T., Bowser, B. P., \& Gross, S. A. (1990). Risk of sexually transmitted disease among black adolescent crack users in Oakland and San Francisco, Calif. Journal of the American Medical Association, 263, 851-855.

Gil-Rivas, V., Fiorentine, R., \& Anglin, M. (1996). Sexual abuse, physical abuse, \& posttraumatic stress disorder among women participating in outpatient drug abuse treatment. Journal of Psychoactive Drugs, 28, 95-102.

Gold, S. R., Milan, L. D., Mayall, A., \& Johnson, A. E. (1994). A cross-validation study of the Trauma Symptom Checklist. Journal of Interpersonal Violence, 9, 12-26.

Gossop, M., Griffiths, B., Powis, B., \& Strang, J. (1993). Severity of heroin dependence and HIV risk. AIDS Care, 5, 149-167.

Gourevitch, M. N., Hartel, D., Schoenbaum, E. E., Selwyn, P. A., Davenny, K., Friedland, G. H., \& Klein, R. S. (1996). A prospective study of the association of syphilis and HIV infection in injecting drug users. American Journal of Public Health, 86, 112-115.

Green, S. T., Goldberg, D. J., Christie, P. R., Frischer, M., Thomson, A., Carr, S. V., \& Taylor, A. (1994). Female street worker-Prostitutes in Glasgow: A descriptive study of their lifestyle. AIDS Care, 5, 321-335.

Grella, C. E., Anglin, D., \& Annon, J. J. (1996). HIV risk behaviors among women in methadone maintenance treatment. Substance Use and Misuse, 31, 277-301.

Hubbard, R. L., Marsden, M. E., Rachal, J. V., Harwood, H. J., Cavanaugh, E. R., \& Ginzburg, H. M. (1989). Drug abuse treatment: A national study of effectiveness. Chapel Hill: University of North Carolina Press.

Inciardi, J. A. (1992). The war on drugs II: The continuing epic of heroin, cocaine, crack, crime, AIDS, and public policy. Mountain View, CA: Mayfield.

Irwin, K., Edlin, B., Wong, L., Faruque, S., McCoy, H., Word, C., Schilling, R., McCoy, C., Evans, P., Holmberg, S., \& the Multicenter Crack Cocaine and HIV Infection Study Team. (1995). Urban rape survivors: Characteristics and prevalence of human immunodeficiency virus and other sexually transmitted infections. Obstetrics and Gynecology, 85, 330-336.

Johnsen, L. W., \& Harlow, L. L. (1996). Childhood sexual abuse linked with adult substance abuse, victimization, and AIDS risk. AIDS Education and Prevention, 8, 44-57. 
Kelly, J. A., Murphy, D. A., Bahr, G. R., Brasfield, T. L., Davis, D. R., Hauth, A. C., Morgan, M. G., Stevenson, C. Y., \& Eilers, M. R. (1992). AIDS/HIV risk behavior among the chronic mentally ill. American Journal of Psychiatry, 149, 886-889.

Kelly, J. A., Murphy, D. A., Bahr, G. R., Koob, J. J., Morgan, M. G., Kalichman, S. C., Stevenson, L. Y., Brasfield, T. L., Bernstein, B. M., \& St. Lawrence, J. S. (1993). Factors associated with severity of depression and high-risk sexual behavior among persons diagnosed with human immunodeficiency virus (HIV) infection. Health Psychology, 12, 215-219.

Kidorf, M., King, V. L., \& Brooner, R. K. (1999). Integrating psychosocial services with methadone treatment: Behaviorally contingent pharmacotherapy. In E. C. Strain \& M. L. Stitzer (Eds.), Methadone treatment for opioid dependence (pp. 166-195). Baltimore: Johns Hopkins University Press.

King, V. L., \& Brooner, R. K. (1999). Assessment and treatment of comorbid psychiatric disorders. In E. C. Strain \& M. L. Stitzer (Eds.), Methadone treatment for opioid dependence (pp. 141-165). Baltimore: Johns Hopkins University Press.

Kleinman, P. H., Miller, A. B., Millman, R. B., Woody, G. E., Todd, T., Kemp, J., \& Lipton, D. S. (1990). Psychopathology among cocaine abusers entering treatment. Journal of Nervous and Mental Disease, 178, 442-447.

Lesswing, N. J., \& Dougherty, R. J. (1993). Psychopathology in alcohol and cocaine-dependent patients: A comparison of findings from psychological testing. Journal of Substance Abuse Treatment, 10, 53-57.

Malow, R. M., West, J. A., Williams, J. L., \& Sutker, P. B. (1989). Personality disorders classification and symptoms in cocaine and opioid addicts. Journal of Consulting and Clinical Psychology, 57, 675-767.

Marx, R., Sevgi, A., Rolfs, R. T., Sterk, C. E., \& Kahn, J. G. (1991). Crack, sex and STD. Sexually Transmitted Diseases, 18, 92-101.

Mason, B. J., Kocsis, J. H., Melia, D., Khuri, E. T., Sweeney, J., Wells, A., Borg, L., Millman, R. B., \& Kreek, M. J. (1998). Psychiatric morbidity in methadone maintained patients. Journal of Addictive Diseases, 17, 75-89.

McBride, D. C., Inciardi, J. A., Cudweed, D. D., \& McCoy, C. B. (1992). Crack use and correlates of use in a national population of street heroin users. Journal of Psychoactive Drugs, 24, 411-416.

McLellan, A. T., Arndt, I. O., Metzger, D. S., Woody, G. E., \& O’Brien, C. P. (1993). The effects of psychosocial services in substance abuse treatment. Journal of the American Medical Association, 269, 1953-1959. 
Mullen, P. E., Martin, J. L., Anderson, J. C., Romans, S. E., \& Herbison, G. P. (1996). The longterm impact of the physical, emotional, and sexual abuse of children: A community study. Child Abuse and Neglect, 20, 7-21.

Nemoto, T., Foster, K., \& Brown, L. S. (1991). Effect of psychological factors on risk behavior of human immunodeficiency virus (HIV) infection among intravenous drug users (IVDUs). International Journal of Addictions, 26, 441-456.

Nolimal, D., \& Crowley, T. (1989). HIV risk behavior: Antisocial personality disorder, drug use patterns, and sexual behavior among methadone maintenance admissions. National Institute on Drug Abuse Research Monograph Series, 95, 401-402.

Nyamathi, A. M. (1992). Relationship of resources to emotional distress, somatic complaints and high-risk behaviors in drug recovery and homeless minority women. Journal of Health Care for the Poor and Underserved, 3, 93-108.

Paone, D., Chavkin, W., Willets, I., Friedman, M., \& Des Jarlais, D. (1992). The impact of sexual abuse: Implications for drug treatment. Journal of Women's Health, 1, 149-153.

Plant, M. L., Plant, M., Peck, D. F., Setters, B. A., \& Setters, J. (1989). The sex industry, alcohol and illicit drugs: Implications for the spread of HIV infection. British Journal of Addiction, 84, 53-59.

Resnick, H., Kilpatrick, D., Dansky, B., Saunders, B., \& Best, C. (1993). Prevalence of civilian trauma and post-traumatic stress disorder in a representative national sample of women. Journal of Consulting and Clinical Psychology, 61, 984-991.

Rolfs, R. T., Goldberg, M., \& Sharrar, R. G. (1990). Risk factors for syphilis: Cocaine use and prostitution. American Journal of Public Health, 80, 853-857.

Roszell, D. K., Calsyn, D. A., \& Chaney, E. F. (1986). Alcohol use and psychopathology in opioid addicts on methadone maintenance. American Journal of Drug Abuse, 12, 269-278.

Schilling, R. F., El-Bassel, N., Hadden, B., \& Gilbert, L. (1995). Skills-training groups to reduce HIV transmission and drug use among methadone patients. Social Work, 40, 91-101.

Schilling, R. F., El-Bassel, N., Ivanoff, A., Gilbert, L., Su, K. H., \& Safyer, S. M. (1994). Sexual risk behavior among incarcerated drug using women. Public Health Reports, 109, 539-546.

Schilling, R. F., El-Bassel, N., Schinke, S., Gordon, K., \& Nichols, S. (1991). Building skills of recovering women drug users to reduce heterosexual AIDS transmission. Public Health Reports, 106, 297-304.

Simoni, J. M., \& Ng, M. (2000). Trauma, coping, and depression among women with HIV/AIDS in New York City. AIDS Care, 12, 567-580. 
Sterk, C. E., \& Elifson, K. W. (1990). Drug-related violence and street prostitution. National Institute on Drug Abuse Research Monograph, 10, 208-221.

Stitzer, M. L., \& Chutuape, M. A. (1999). Other substance use disorders in methadone treatment: Prevalence, consequences, detection, and management. In E. C. Strain \& M. L. Stitzer (Eds.), Methadone treatment for opioid dependence (pp. 86-117). Baltimore: Johns Hopkins University Press.

Straus, M., Gelles, R., \& Steinmetz, S. (1980). Behind closed doors: Violence in the American family. Garden City, NY: Anchor Books.

Susser, E., Valencia, E., \& Conover, S. (1993). Prevalence of HIV infection among psychiatric patients in a New York City men's shelter. American Journal of Public Health, 83, 568-570.

Wells, E. A., Calsyn, D. A., Clark, L. L., Saxon, A. J., \& Jackson, T. R. (1996). Retention in methadone maintenance is associated with reductions in different HIV risk behaviors for women and men. American Journal of Drug and Alcohol Abuse, 22, 509-521.

Windle, M., Windle, R., Scheidt, P., \& Miller, G. (1995). Physical and sexual abuse and associated mental disorders among alcoholic inpatients. American Journal of Psychiatry, 152, 1322-1328.

Zierler, S., Feingold, L., Laufer, D., Velentgas, P., Kantrowitz-Gordon, I., \& Mayer, K. (1991). Adult survivors of childhood sexual abuse and subsequent risk of HIV infection. American Journal of Public Health, 81, 572-575.

Zlotnick, C., Warsaw, M., Shea, M. T., \& Keller, M. B. (1997). Trauma and chronic depression among patients with anxiety disorders. Journal of Consulting and Clinical Psychology, 65, 333336.

Zweig Greenberg, M. S., Singh, T., Htoo, M., \& Schultz, S. (1991). The association between congenital syphilis and cocaine/crack use in New York City: A case-control study. American Journal of Public Health, 81, 1316-1318. 